\title{
Studi Eksperimen Dan Numerik Pengaruh Slat Clearance Serta Slat Angle Untuk Mengeliminasi Stall Pada Airfoil "Studi kasus airfoil NACA 2412"
}

\author{
Arwanda Wahyu Eko Sadewo dan Herman Sasongko \\ Jurusan Teknik Mesin, Fakultas Teknologi Industri, Institut Teknologi Sepuluh Nopember (ITS) \\ Jln. Arif Rahman Hakim, Surabaya 60111 Indonesia \\ e-mail : herman@me.its.ac.id
}

\begin{abstract}
Abstrak-Fase take off dan landing merupakan fase yang paling kritis diantara fase - fase dalam operasi penerbangan. Pada saat take off sayap pesawat diposisikan pada angle of attack yang cukup besar, sehingga aliran udara akan melawan adverse pressure yang lebih besar sampai saat dimana aliran tidak mampu melawan adverse pressure aliran akan terseparasi. Jika terjadi separasi permanen sesaat setelah aliran melintasi leading edge di sektor upper side maka bisa mengakibatkan terjadinya stall pada pesawat. Untuk mencegah hal tersebut terjadi, dibutuhkan slat pada bagian depan sayap sebagai penuntun aliran pada leading edge untuk memasuki daerah upper side secara halus dengan akselerasi yang kuat. Penelitian ini dilakukan dengan eksperimen dan numerik. Benda uji yang digunakan adalah airfoil NACA 2412 dengan slat dan tanpa slat. Variasi slat clearance dan slat angle yaitu $S / c: 0,05 ; 0,07 ; 0,09 ;(\beta): 0^{\circ}, 3^{\circ}, 5^{\circ}$. Hasil penelitian ini adalah konfigurasi B merupakan konfigurasi optimum dalam mengeliminasi stall pada angle of attack $(\alpha) 8^{\circ}$, sedangkan konfigurasi $H$ merupakan konfigurasi optimum dalam mengeliminasi stall pada angle of attack $(\alpha) 16^{\circ}$.
\end{abstract}

Kata kunci-airfoil NACA 2412, slat, slat angle, slat clearance.

\section{PENDAHULUAN}

I ndonesia sebagai Negara dengan ekonomi terbesar di kawasan Asia Tenggara, memiliki peningkatan permintaan layanan transportasi udara, baik tujuan domestik maupun internasional. Meningkatnya permintaan ini sejalan dengan pemeratan pembangunan serta bentuk Negara Indonesia yang terdiri atas banyak pulau. Namun seiring dengan meningkatnya permintaan layanan tranportasi udara, kecelakaan pada alat transportasi udara juga ikut meningkat.

Fase take off dan landing merupakan fase yang paling kritis diantara fase - fase dalam operasi penerbangan. Pada saat take off sayap pesawat diposisikan pada angle of attack yang cukup besar, sehingga aliran udara pada sayap yang melewati upper side akan dipaksa bergerak dengan kecepatan yang lebih tinggi lagi dibandingkan dengan udara yang bergerak pada bagian lower side. Kejadian ini dapat menimbulkan separasi permanen lapis batas pada leading edge airfoil. Saat pesawat dalam posisi take off akan menyebabkan pergeseran titik stagnasi ke daerah lower side dari leading edge airfoil. Pergeseran titik stagnasi ini akan memaksa aliran udara masuk ke daerah upper side dengan percepatan yang sangat kuat (strong accelerated flow) dengan lintasan berbentuk S. Setelah melawati leading edge dengan percepatan kuat segera disusul terbentuknya divergensi stream tube yang mengakibatkan perlambatan secara tiba - tiba dengan tekanan yang naik mendadak. Terbentuknya divergensi stream tube yang kuat pada leading edge mengakibatkan adanya adverse pressure gradient yang besar dan terbentuknya vortex separation. Jika separasi permanen tersebut sudah terjadi sesaat setelah aliran melintasi leading edge di sektor upper side maka bisa mengakibatkan terjadinya stall pada pesawat. Untuk mencegah hal tersebut terjadi, dibutuhkan slat pada bagian depan sayap sebagai penuntun aliran pada leading edge untuk memasuki daerah upper side secara halus dengan akselerasi yang kuat.

Studi terdahulu mengenai slat telah diteliti oleh Souza et al [1] yang membahas efek aliran pada slat dan airfoil. Penelitian ini meneliti dampak aliran antara slat dan airfoil dengan memvariasikan bentuk slat dengan seal dan tanpa seal. Penelitian ini menggunakan model airfoil MD30P30N dengan variasi bentuk slat berdasarkan simulasi dua dimensi dan tiga dimensi. Hasil yang didapatkan dalam percobaan ini adalah dengan penambahan seal pada slat akan meminimalkan separasi aliran pada leading edge airfoil. Studi lainnya tentang slat juga pernah diteliti oleh Ge et al [2]. Ge meneliti bentuk slat serta airfoilnya mengadaptasi dari bentuk sayap burung hantu. Penelitian ini dilakukan dengan memvariasikan besarnya angle of attact, dan bentuk dari airfoil dengan simulasi dua dimensi. Dalam penelitiannya, Ge menyatakan bahwa penambahan slat pada airfoil dapat menambah maksimal koefisien lift, dan stall angle. Penelitian mengenai slat pernah dilakukan oleh Tung et al[3]. Tung meneliti tentang pengaruh stall angle pada airfoil dengan slat dan tanpa slat. Dalam penelitian ini Tung menggunakan airfoil VR-7 dan variasi angle of attack dengan eksperimen menggunakan water tunnel. Dari penelitian ini didapatkan bahwa penambahan slat pada airfoil dapat menunda stall angle. Studi lainnya juga pernah dilakukan oleh Savory et al [4] mengenai Slat. Savory meneliti aliran pada daerah cove diantara slat dan sayap serta daerah cove diantara sayap dan flap pada multielemen airfoil. Percobaan ini akan menginvestigasi medan aliran pada daerah cove menggunakan model airfoil seri A-300, dengan variasi geometri slat dan flap. Dari percobaan ini didapatkan pada flap 
memiliki pengaruh yang sedikit dalam menunda terjadinya separasi dibandingkan dengan slat.

Akibat penggabungan jet flow dari celah slat dan aliran yang melintasi suction side slat akan mengakibatkan vortex. Vortex tersebut dapat menyebabkan aliran terdefleksi yang akan mengakibatkan blockage aliran. Ketika blockage aliran terlalu besar, luasan efektif akan berkurang sehingga menyebabkan terjadinya stall. Oleh karena itu, pada penelitian ini dipilih variasi jarak slat dan slat angle untuk menghindari terjadinya blockage pada suction side airfoil utama. Rekayasa pertama dipilih vasiasi jarak slat terhadap airfoil utama pada angle of attack tertentu untuk mendapatkan kekuatan momentum yang besar pada suction side airfoil. Rekayasa kedua adalah dengan memvariasikan slat angle untuk mensinergikan vektor kecepatan outlet slat clearance dan vektor kecepatan outlet suction side slat. Pemilihan variasi jarak dan slat angle ini dapat mengarahkan semburan aliran celah untuk meniadakan terjadinya separasi aliran pada zona leading edge dan menunda separasi aliran zona buritan suction side dari airfoil utama. Sehingga stall pada airfoil dapat tereliminasi.

\section{METODOLOGI PENELITIAN}

Pada penelitian ini, dapat terlihat skema model dan konfigurasi uji yang akan dilakukan pengukuran seperti pada gambar 1 dan tabel 1 berikut

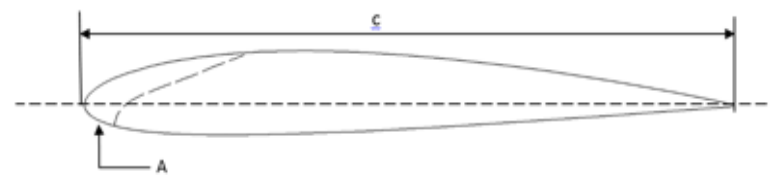

(i)

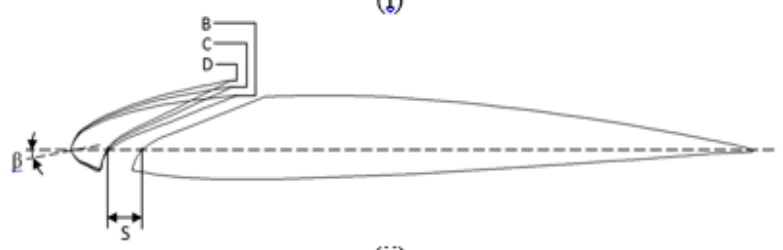

(ii)

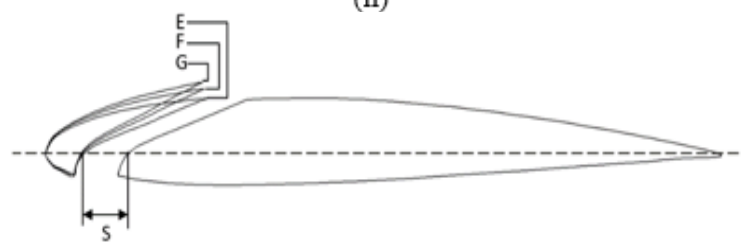

(iii)

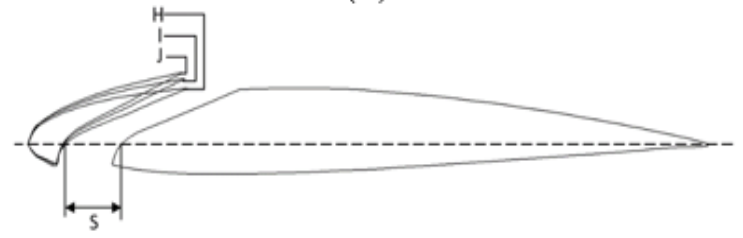

(iv)

Gambar 1. (i) NACA 2412; (ii) Penambahan slat dengan jarak 5\% c; (iii) Penambahan slat dengan jarak $7 \% \mathrm{c}$; (iv) Penambahan slat dengan jarak $9 \% \mathrm{c}$

Tabel 1.
Keterangan konfigurasi slat

\begin{tabular}{ccc}
\hline \hline Konfigurasi & $\boldsymbol{S} / \boldsymbol{c}$ & $\boldsymbol{\beta}$ \\
\hline A & 0 & $0^{\circ}$ \\
B & 0.05 & $0^{\circ}$ \\
C & 0.05 & $3^{\circ}$ \\
D & 0.05 & $5^{\circ}$ \\
E & 0.07 & $0^{\circ}$ \\
F & 0.07 & $3^{\circ}$ \\
G & 0.07 & $5^{\circ}$ \\
H & 0.09 & $0^{\circ}$ \\
I & 0.09 & $3^{\circ}$ \\
J & 0.09 & $5^{\circ}$ \\
\hline \hline
\end{tabular}

\section{Spesifikasi Wind Tunnel}

Jenis wind tunnel: subsonic, open circuit wind tunnel seperti yang ditujukkan gambar 2

Bentuk saluran uji: penampang segi 4

- Panjang : $1780 \mathrm{~mm}$

- Tinggi : $660 \mathrm{~mm}$

- Lebar : $660 \mathrm{~mm}$

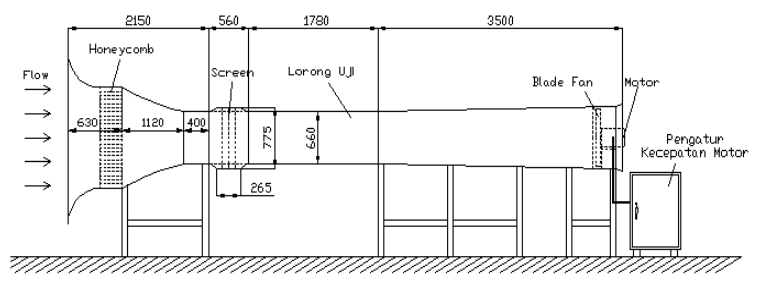

Gambar 2. Skema Wind Tunnel Sub Sonic

\section{Benda Uji}

Profil airfoil NACA 2412 dan NACA 2412 dengan slat dapat dilihat pada gambar 3. Dengan dimensi sebagai berikut :
- $\quad$ Chord (c)
: $170 \mathrm{~mm}$
- $\operatorname{Span}(\mathrm{L})$
: $750 \mathrm{~mm}$

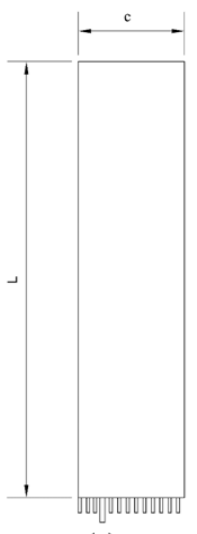

(a)

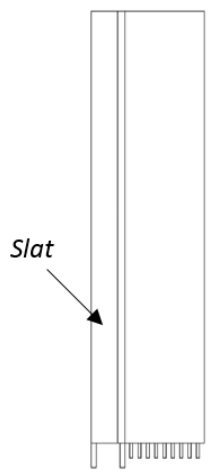

(b)
Gambar 3. Tampak atas airfoil NACA 2412 tanpa slat (a) dan dengan slat (b)

Alat

Ukur

a. Pitot static tube

b. Manometer

Inclined manometer $15^{\circ}$ dengan fluida red oil $\mathrm{SG}=0,80$

c. Data logger dan pressure transducer

d. Termometer

Metode Pengambilan Data Eksperimen 


\section{- Pengukuran Tekanan Statis}

Pengukuran tekanan statis diperlukan untuk mengetahui kontur tekanan permukaan pada airfoil utama. Pengukuran tekanan statis dilakukan di mid span menggunakan pressure tap pada upper side dan lower side

\section{- Visualisasi Aliran}

Visualisasi aliran diperlukan untuk mengetahui fenomena skin friction line dari aliran fluida pada kontur permukaan secara kualitatif

\section{Metode Numerik}

Penelitian secara numerik dilakukan untuk mempertegas hasil yang didapat dari eksperimen

\section{Pre-processing}

A. Model Uji

Model uji berupa airfoil NACA 2412 dengan slat dan tanpa slat pada angle of attack $8^{\circ}$, dan $16^{\circ}$.

B. Domain Simulasi

Simulasi menggunakan domain seperti gambar 4

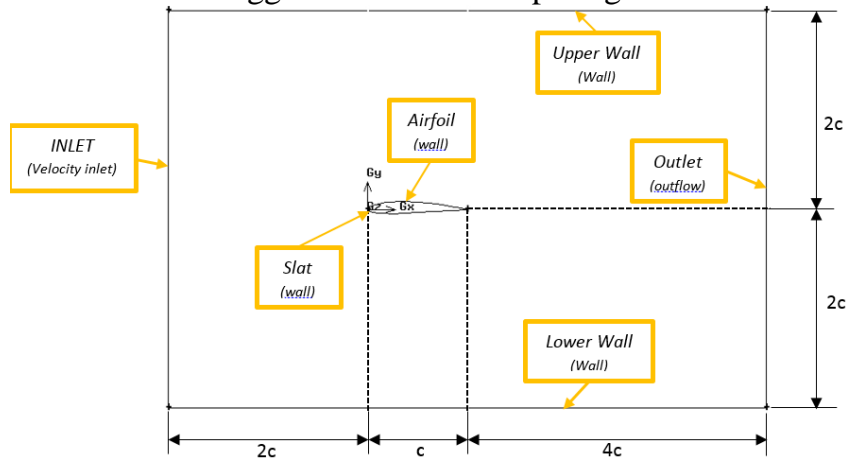

Gambar 4. Domain simulasi NACA 2412

C. Meshing

D. Menentukan Kondisi Batas

\section{Processing}

A. Models

Turbulence model yang digunakan pada penelitian ini adalah $\boldsymbol{k}-\boldsymbol{\varepsilon}$ standard

B. Materials

Pemodelan ini menggunakan udara sebagai fluida kerja dengan densitas $(\rho)=1,17 \mathrm{~kg} / \mathrm{m}^{3}$, viskositas $(\mu)=1,86 \mathrm{x}$ $10^{-5} \mathrm{~N} . \mathrm{s} / \mathrm{m}^{2}$

C. Operating Condition

daerah operasi digunakan standard dan pressure yaitu 1 atm atau 101325 Pascal

D. Boundary Condition

bilangan Reynolds pada inlet wind tunnel $\operatorname{Re}=1,6 \times 10^{5}$ dan kecepatan free stream sebesar $15 \mathrm{~m} / \mathrm{s}$.

E. Solution

Penelitian ini akan menggunakan deskritisasi second order untuk pressure, second order upwind untuk momentum, turbulence kinetic energy dan turbulence dissipation rate.

\section{F. Initialize}

Initialize dihitung dari inlet

G. Monitor Residual

Kriteria konvergensi yang digunakan dalam penelitain ini sebesar $10^{-5}$

H. Iterate

\section{ANALISIS DATA DAN PEMBAHASAN}

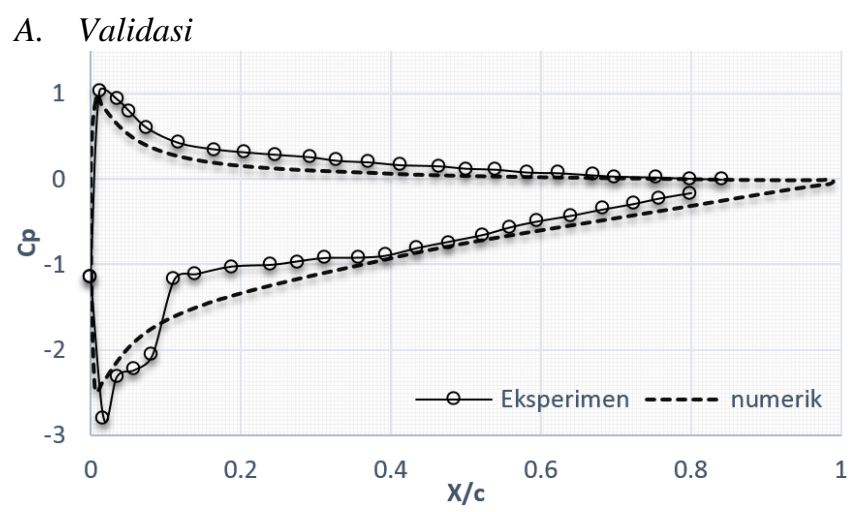

Gambar 5. Grafik $\mathrm{Cp}$ fungsi $\mathrm{X} / \mathrm{c}$ perbandingan hasil eksperimen dan numerik pada airfoil NACA 2412

Dari gambar 5 terlihat bahwa hasil Cp pada numerik dan eksperimen memiliki trend line garis yang sama. Pada hasil eksperimen dan numerik memiliki nilai masksimum $\mathrm{Cp}$ yang sama - sama mendekati 1 . Sedangkan nilai minimum $\mathrm{Cp}$ numerik sebesar -2,48 dan nilai minimum Cp eksperimen yang didapatkan sebesar $-2,80$. Dari perbandingan dua grafik diatas dapat disimpulkan trend garis antara studi numerik dan eksperimen hampir sama, perbedaan terjadi akibat faktor faktor eksternal yang tidak di sertakan pada studi numerik seperti turbulent intensity, perubahan suhu dan lain-lain. Nilai Cp eksperimen tidak mencapai X/c $=1$ karena pemasangan alat ukur yang tidak mampu dipasang pada model airfoil NACA 2412 akibat celah model yang sempit.

\section{B. Analisis Karakteristik Aliran}

\section{- Karakteristik Aliran Pada Slat Clearence 5\%}
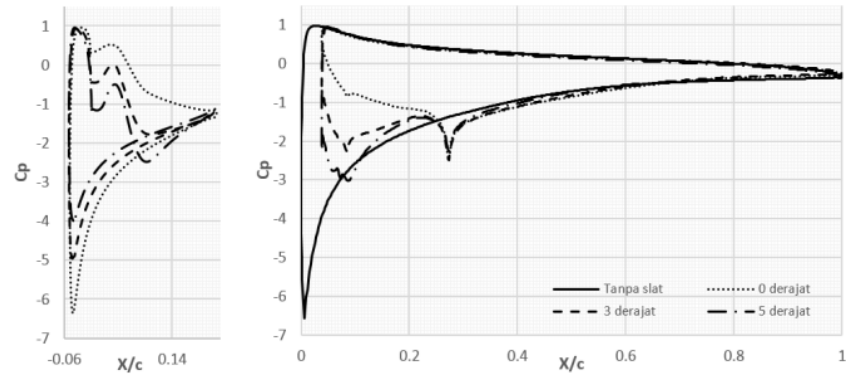

Gambar 6. Grafik Cp fungsi X/c hasil numerik pada $\alpha=16^{\circ}, R e=1.6 \times 10^{5}$ slat clearance $5 \%$ dengan slat angle $0^{0}, 3^{0}, 5^{0}$, dan tanpa slat

Gambar 6 menunjukkan hasil numerik distribusi koefisien tekanan (Cp) fungsi X/c pada airfoil NACA 2412 angle of attack $(\alpha)=16^{\circ}$ dengan slat dan tanpa slat pada slat clearance $5 \%$. Pengukuran koefisien tekanan secara numerik dilakukan pada airfoil utama. oleh karena itu panjang airfoil utama tanpa slat lebih panjang dibandingkan dengan airfoil dengan slat. Slope pada airfoil tanpa slat memiliki trend line yang lebih dalam dibandingkan pada grafik konfigurasi tanpa slat. Besar nilai Cp pada airfoil NACA 2412 tanpa slat juga memiliki nilai Cp upper side yang lebih rendah dibandingkan dengan konfigurasi lainnya. Hal ini membuktikan pada celah antara slat dan airfoil aliran udara cenderung melambat pada bagian celah slat. Koefisien tekanan $(\mathrm{Cp})$ terendah terjadi pada 
konfigurasi tanpa slat dengan nilai Cp sebesar -6,56 sedangkan pada konfigurasi slat koefisien tekanan $(\mathrm{Cp})$ terendah terjadi pada konfigurasi $5^{\circ}$ dengan nilai $\mathrm{Cp}$ sebesar $-3,01$.
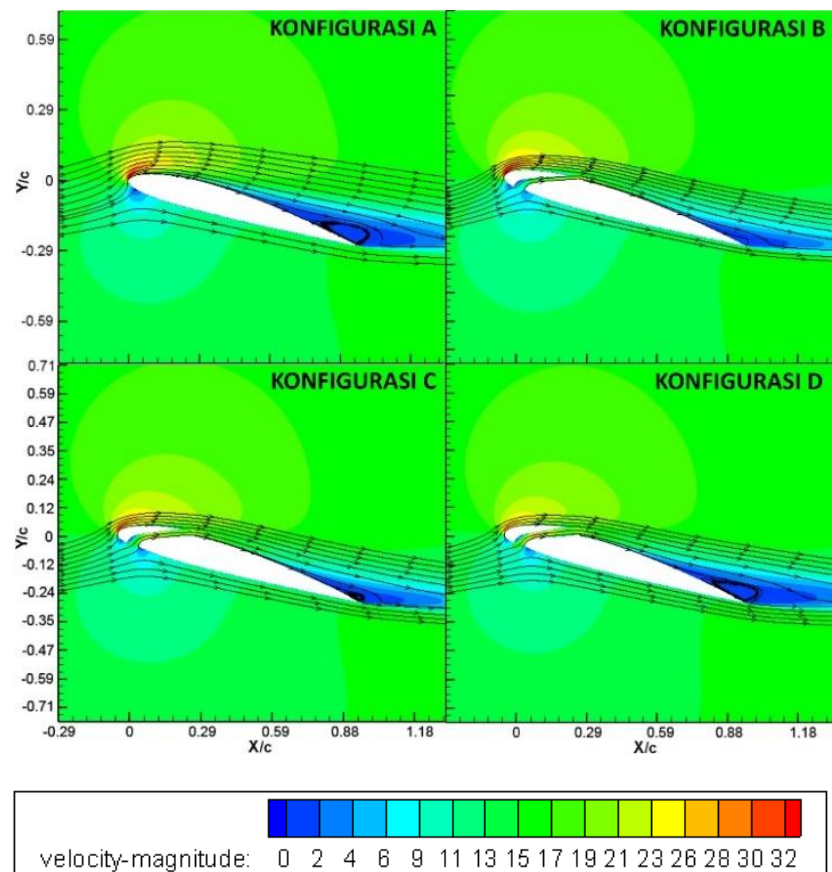

Gambar 7. Visualisasi aliran pemodelan airfoil NACA 2412 pada $\alpha=16^{\circ}$ dengan $R e=1.6 \times 10^{5}$ konfigurasi A, B, C, dan D

Gambar 7 menunjukkan visualisasi numerik aliran pada airfoil NACA 2412 dengan slat dan tanpa slat pada angle of attack $16^{\circ}$. Penambahan slat pada airfoil terbukti mampu menunda separasi dan memperkecil vortex aliran yang terjadi pada bagian buritan airfoil. Tampak dari visualisasi aliran di sekitar leading edge pada gambar $7 \mathrm{~B}$ dan C momentum aliran yang melewati celah akan bertambah besar akibat melalui celah konvergen. Indikasi awal mengenai adanya Bubble separation yang muncul pada bagian bawah slat telah terbukti, hal tersebut dapat dilihat pada gambar 7 B, C, dan D. Bubble separation ini dapat timbul akibat momentum aliran lemah yang melalui bagian lower side slat bertemu dengan aliran $\mathrm{S}$ curve bermomentum sangat besar sehingga menimbulkan blockage aliran.

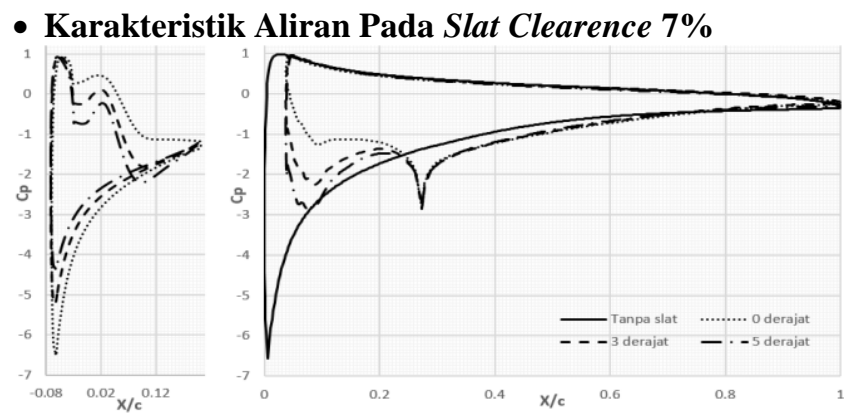

Gambar 8. Grafik Cp fungsi X/c hasil numerik pada $\alpha=16^{\circ}, R e=1.6 \times 10^{5}$ slat clearance $7 \%$ dengan slat angle $0^{0}, 3^{0}, 5^{0}$, dan tanpa slat

Gambar 8 menunjukkan hasil numerik distribusi koefisien tekanan (Cp) fungsi X/c pada airfoil NACA 2412 angle of attack $(\alpha)=16^{\circ}$ dengan slat dan tanpa slat pada slat clearance $5 \%$. Pengukuran koefisien tekanan secara numerik dilakukan pada airfoil utama. oleh karena itu panjang airfoil utama tanpa slat lebih panjang dibandingkan dengan airfoil dengan slat. Slope pada airfoil tanpa slat memiliki trend line yang lebih dalam dibandingkan pada grafik konfigurasi tanpa slat. Besar nilai Cp pada airfoil NACA 2412 tanpa slat juga memiliki nilai $\mathrm{Cp}$ upper yang lebih rendah dibandingkan dengan konfigurasi lainnya. Hal ini membuktikan pada celah antara slat dan airfoil aliran udara cenderung melambat pada bagian celah slat. Koefisien tekanan $(\mathrm{Cp})$ terendah terjadi pada konfigurasi tanpa slat dengan nilai $\mathrm{Cp}$ sebesar -6,56 sedangkan pada konfigurasi slat koefisien tekanan $(\mathrm{Cp})$ terendah terjadi pada konfigurasi $5^{\circ}$ dengan nilai $\mathrm{Cp}$ sebesar -3,01.

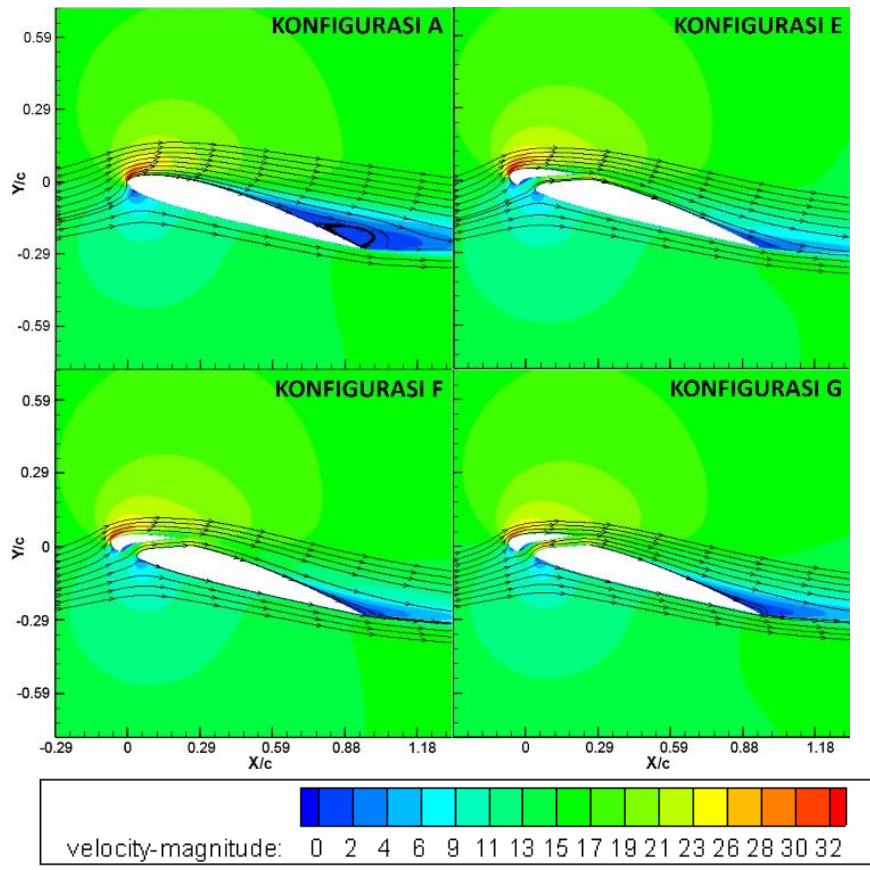

Gambar 9. Visualisasi aliran pemodelan airfoil NACA 2412 pada $\alpha=16^{\circ}$ dengan $R e=1.6 \times 10^{5}$ konfigurasi $\mathrm{A}, \mathrm{E}, \mathrm{F}$, dan $\mathrm{G}$

Gambar 9 menunjukkan visualisasi numerik aliran pada airfoil NACA 2412 dengan slat dan tanpa slat pada angle of attack $16^{\circ}$. Penambahan slat pada airfoil terbukti mampu menunda separasi dan memperkecil vortex aliran yang terjadi pada bagian buritan airfoil. Tampak dari visualisasi aliran di sekitar leading edge pada gambar $9 \mathrm{E}$ dan F momentum aliran yang melewati celah akan bertambah besar akibat melalui celah konvergen. Indikasi awal mengenai adanya bubble separation yang muncul pada bagian bawah slat telah terbukti, hal tersebut dapat dilihat pada gambar 9 E, F, dan G. Bubble separation ini dapat timbul akibat momentum aliran lemah yang melalui bagian lower side slat bertemu dengan aliran S curve bermomentum sangat besar sehingga menimbulkan blockage aliran.

- Karakteristik Aliran Pada Slat Clearence 9\% 

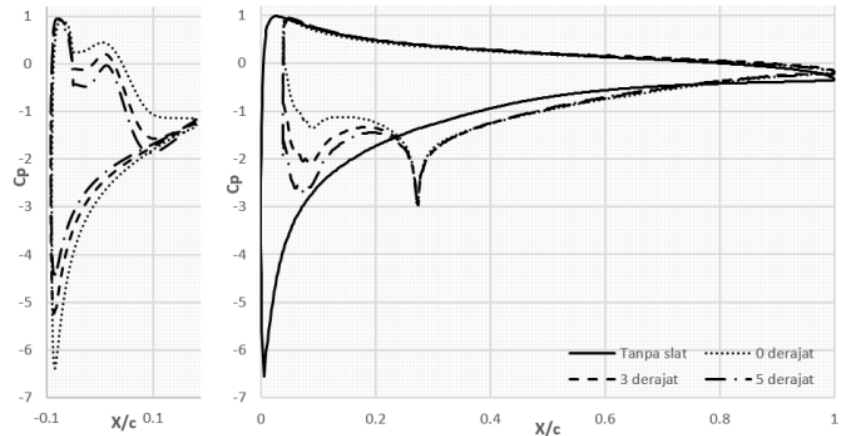

Gambar 10. Grafik Cp fungsi X/c hasil numerik pada $\alpha=16^{\circ}, R e=1.6 \times 10^{5}$ slat clearance $7 \%$ dengan slat angle $0^{0}, 3^{0}, 5^{0}$, dan tanpa slat

Gambar 10 menunjukkan hasil numerik distribusi koefisien tekanan (Cp) fungsi X/c pada airfoil NACA 2412 angle of attack $(\alpha)=16^{\circ}$ dengan slat dan tanpa slat pada slat clearance $9 \%$. Pengukuran koefisien tekanan secara numerik dilakukan pada airfoil utama. Oleh karena itu panjang airfoil utama tanpa slat lebih panjang dibandingkan dengan airfoil dengan slat. Slope pada airfoil tanpa slat memiliki trend line yang lebih dalam dibandingkan pada grafik konfigurasi tanpa slat. Besar nilai Cp pada airfoil NACA 2412 tanpa slat juga memiliki nilai Cp upper yang lebih rendah dibandingkan dengan konfigurasi lainnya. Hal ini membuktikan pada celah antara slat dan airfoil aliran udara cenderung melambat pada bagian celah slat. Koefisien tekanan $(\mathrm{Cp})$ terendah terjadi pada konfigurasi tanpa slat dengan nilai $\mathrm{Cp}$ sebesar $-6,56$ sedangkan pada konfigurasi slat koefisien tekanan $(\mathrm{Cp})$ terendah terjadi pada konfigurasi $5^{\circ}$ dengan nilai $\mathrm{Cp}$ sebesar $-3,01$.

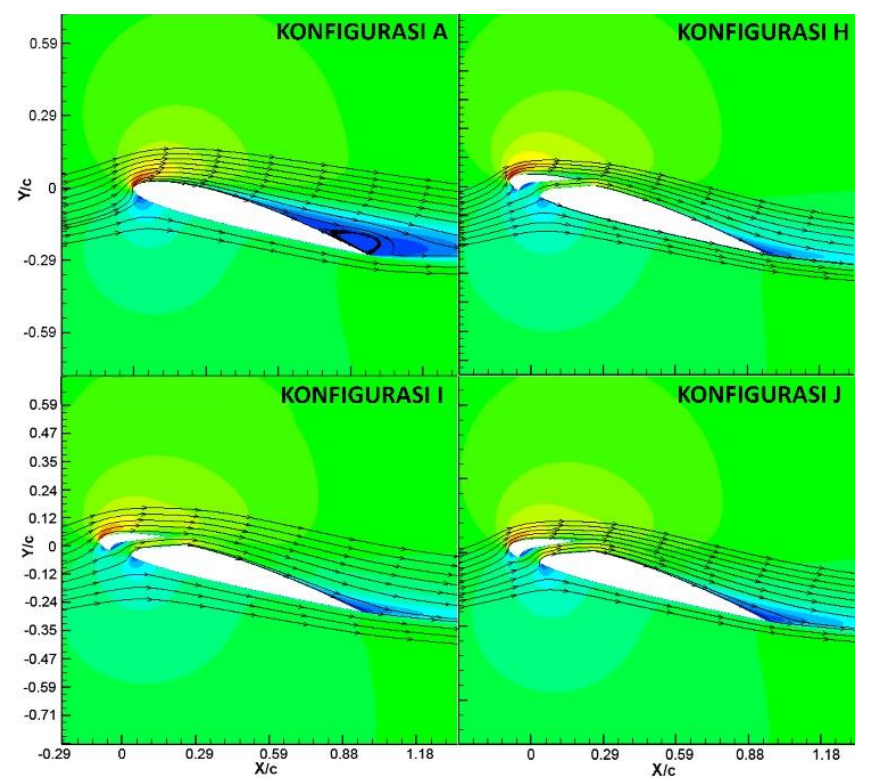

Gambar 11. Visualisasi aliran pemodelan airfoil NACA 2412 pada $\alpha=16^{\circ}$ dengan $R e=1.6 \times 10^{5}$ konfigurasi $\mathrm{A}, \mathrm{H}, \mathrm{I}$, dan $\mathrm{J}$

Gambar 11 menunjukkan visualisasi numerik aliran pada airfoil NACA 2412 dengan slat dan tanpa slat pada angle of attack $16^{\circ}$. Penambahan slat pada airfoil terbukti mampu menunda separasi dan memperkecil vortex aliran yang terjadi pada bagian buritan airfoil. Tampak dari visualisasi aliran di sekitar leading edge pada gambar 11 konfigurasi $\mathrm{H}$ dan I momentum aliran yang melewati celah akan bertambah besar akibat melalui celah konvergen. Indikasi awal mengenai adanya bubble separation yang muncul pada bagian bawah slat telah terbukti, hal tersebut dapat dilihat pada gambar 11 konfigurasi H, I, dan J. Bubble separation ini dapat timbul akibat momentum aliran lemah yang melalui bagian lower side slat bertemu dengan aliran S curve bermomentum sangat besar sehingga menimbulkan blockage aliran.

\section{Hasil koefisien Lift dan koefisien Drag numerik}

Tabel 2.

Keterangan konfigurasi slat

\begin{tabular}{cccc}
\hline \hline Konfigurasi & Cl & Cd & Cl/Cd \\
\hline A & 1.362 & 0.135 & 10.092 \\
B & 1.503 & 0.131 & 11.459 \\
C & 1.430 & 0.135 & 10.559 \\
D & 1.305 & 0.142 & 9.208 \\
E & 1.606 & 0.136 & 11.850 \\
F & 1.558 & 0.136 & 11.433 \\
G & 1.466 & 0.137 & 10.685 \\
H & 1.660 & 0.137 & 12.124 \\
I & 1.628 & 0.135 & 12.047 \\
J & 1.568 & 0.135 & 11.653 \\
\hline \hline
\end{tabular}

Tabel 2 menunjukkan besarnya nilai koefisien lift $\left(\mathrm{C}_{\mathrm{L}}\right)$ airfoil NACA 2412 dengan slat dan tanpa slat pada angle of attack $16^{0}$ pada $R e=1.6 \times 10^{5}$. Dari tabel 2 dapat diketahui semakin bertambahnya slat clearance besarnya koefisien lift semakin meningkat. Besar nilai koefisien lift terbesar terjadi pada konfigurasi $\mathrm{H}$ yaitu airfoil dengan slat angle $(\beta) 0^{\circ}$ dan slat clearance $(\mathrm{S} / \mathrm{c})$ 9\% dengan koefisien lift $\left(\mathrm{C}_{\mathrm{L}}\right)$ sebesar 1.660. Hal ini dapat dilihat dari visualisasi aliran disekitar airfoil, vortex dibagian buritan airfoil semakin kecil sehingga menambah luasan airfoil penghasil lift di zona buritan airfoil. Nilai koefisien lift terendah terjadi pada konfigurasi D dengan koefisien lift sebesar 1.305. Pada konfigurasi D, vortex aliran pada zona buritan tidak berhasil dikurangi sehingga lift yang dihasilkan lebih kecil dibandingkan dengan konfigurasi lainnya

Tabel 2 menunjukkan besarnya nilai koefisien $\operatorname{drag}\left(\mathrm{C}_{\mathrm{D}}\right)$ airfoil NACA 2412 dengan slat dan tanpa slat pada angle of attack $16^{0}$ pada $R e=1.6 \times 10^{5}$. Dari tabel 2 dengan penambahan slat clearance besarnya koefisien drag belum tentu berkurang dibandingkan tanpa slat. Penurunan nilai koefisien drag terkecil terjadi pada konfigurasi B yaitu dengan slat clearance $5 \% \mathrm{C}$ dan slat angle $0^{0}$ dengan besar nilai koefisien drag $\left(\mathrm{C}_{\mathrm{D}}\right)$ sebesar 0.131. Sedangkan koefisien drag terbesar terjadi pada konfigurasi D dengan nilai koefisien drag sebesar 0.142 . Besarnya drag yang terjadi disebabkan adanya blockcage aliran pada bagian lower side slat dan vortex yang terjadi di zona buritan airfoil utama

Perbandingan antara koefisien lift $\left(\mathrm{C}_{\mathrm{L}}\right)$ dan koefisien drag

velocity-magnitude: $\quad 0 \quad 2 \quad 4 \quad 6 \quad 961113151719212326283032$

$\left(C_{D}\right)$ merupakan salah satu cara untuk mengetahui konfigurasi yang paling optimal dari konfigurasi yang ada. Tabel 2 menujukkan perbandingan $\mathrm{C}_{\mathrm{L}} / \mathrm{C}_{\mathrm{D}}$ airfoil NACA 2412 dengan slat dan tanpa slat pada angle of attack $16^{0}$ pada $R e=1,6 \times 10^{5}$. Dari tabel 2 diketahui konfigurasi terbaik dengan meninjau perbandingan koefisien lift $\left(\mathrm{C}_{\mathrm{L}}\right)$ dan koefisien $\operatorname{drag}\left(\mathrm{C}_{\mathrm{D}}\right)$ adalah 
konfigurasi $\mathrm{H}$ dengan besar nilai perbandingan $\mathrm{C}_{\mathrm{L}} / \mathrm{C}_{\mathrm{D}} 12.124$. Sedangkan konfigurasi dengan meninjau perbandingan koefisien lift $\left(\mathrm{C}_{\mathrm{L}}\right)$ dan koefisien drag $\left(\mathrm{C}_{\mathrm{D}}\right)$ terendah adalah konfigurasi $D$ dengan besar nilai perbandingan $C_{L} / C_{D} 9.208$.

\section{A. Kesimpulan}

\section{PENUTUP}

Setelah menganalisis karakteristik aliran Airfoil NACA 2412 didapatkan kesimpulan sebagai berkut.

1. Konfigurasi optimum variasi slat angle pada angle of attack $(\alpha) 8^{\circ}$ adalah konfigurasi B dengan slat angle $(\beta) 0^{\circ}$. Besar $\mathrm{C}_{\mathrm{L}}$ dan $\mathrm{C}_{\mathrm{D}}$ yang dihasilkan dari konfigurasi $\mathrm{B}$ adalah 0.918 dan 0.056 dengan besar $C_{L} / C_{D}$ adalah 16.453

2. Konfigurasi optimum variasi slat clearance pada angle of attack $(\alpha) 8^{\circ}$ adalah konfigurasi B dengan slat clearance (S/c) 5\%. Besar $\mathrm{C}_{\mathrm{L}}$ dan $\mathrm{C}_{\mathrm{D}}$ yang dihasilkan dari konfigurasi $\mathrm{B}$ adalah 0.918 dan 0.056 dengan besar $\mathrm{C}_{\mathrm{L}} / \mathrm{C}_{\mathrm{D}}$ adalah 16.453

3. Konfigurasi optimum variasi slat angle pada angle of attack $(\alpha) 16^{\circ}$ adalah konfigurasi $\mathrm{H}$ dengan slat angle $(\beta) 0^{\circ}$. Besar $\mathrm{C}_{\mathrm{L}}$ dan $\mathrm{C}_{\mathrm{D}}$ yang dihasilkan dari konfigurasi $\mathrm{H}$ adalah 1.660 dan 0.137 dengan besar $\mathrm{C}_{\mathrm{L}} / \mathrm{C}_{\mathrm{D}}$ adalah 12.124

4. Konfigurasi optimum variasi slat clearance pada angle of attack $(\alpha) 16^{\circ}$ adalah konfigurasi $\mathrm{H}$ dengan slat clearance (S/c) 9\%. Besar $C_{L}$ dan $C_{D}$ yang dihasilkan dari konfigurasi $\mathrm{H}$ adalah 1.660 dan 0.137 dengan besar $\mathrm{C}_{\mathrm{L}} / \mathrm{C}_{\mathrm{D}}$ adalah 12.124

\section{B. Saran}

Berikut merupakan beberapa saran yang dapat diberikan setelah penelitian dilakukan untuk penelitian berikutnya adalah :

1. Konfigurasi angle of attack dapat diuji kembali dengan sudut yang lebih ekstrim untuk mengetahui optimasi sudut slat pada airfoil.

2. Konfigurasi slat clearance tidak hanya digeser searah sumbu $\mathrm{X}$ namun juga divariasikan kearah sumbu $\mathrm{Y}$ untuk mengetahui pengaruh posisi slat pada optimalisasi lift dari airfoil

\section{DAFTAR PUSTAKA}

[1] Souza, D.S., Rodriguez, D., Simoes, L.G.C., Medeiros, M.A.F, 2014. Effect of an excrescene in the slat cove : Flow-field, acoustic radiation and coherent structures. Aerospace Science and Technology. 2015, vol 44. Pp.108-115

[2] Ge, C., Ren, L., Liang, P., Zhang, C., Zhang, Z. 2013. High-Lift Effect of Bionic Slat Based on Owl Wing. Journal of Bionic Engineering 2013, vol 10, Pp. 456-463

[3] Tung, C., McAlister, K.W., Wang, C.M. 1993. Unsteady Aerodynamic Behavior of An Airfoil With and Without a Slat. Computers Fluids Vol. 22, No. 4/5, Pp. 529-547

[4] Savory, E., Toy, N., Tahouri, B., Dalley, S. 1992. Flow Regimes in the Cove Region Between a Slat and Wing and Between a Wing and Flap of a Multielement Airfoil. Experimental Thermal and Fluid Science 1992 Vol. 5, Pp. 307-316 